\title{
Evaluation of the quality of life and sociodemographic features of patients with muscular dystrophies
}

\author{
Askeri Turken ${ }^{1}$ \\ ${ }^{1}$ Affiliation not available
}

March 23, 2021

\begin{abstract}
Objective: Muscular dystrophies refers to a group of primary inherited myopathies that exhibit a chronic and unremitting progressive course. Quality of life is a concept, which mainly reflects individual responses given by a person to the physical, psychological, social and environmental impacts of the disease. In this study we aimed to evaluate quality of life and sociodemographic features of 146 patients who presented to the physical therapy and rehabilitation neuromuscular diseases outpatient clinic of our hospital. Methods: Patients' sociodemographic data including gender, marital status and educational level were recorded and analyzed. WHOQOL-BREF survey was performed in order to determine quality of life in patients with muscular dystrophy. The scores obtained from the survey were transformed into WHOQOL 4-20 and WHOQOL 0-100 score ranges, and relationships between the sociodemographic data of the patients and WHOQOL-BRIEF survey results were evaluated. Results: Eighty-five $(58.2 \%)$ patients were male and $61(41.8 \%)$ were female. No statistically significant difference was found between the male and female MD patients in terms of the physical, psychological, social relationships and environmental domains of WHOQOL-BREF scale (for all p>0.05). No significant difference was found between single, married, divorced and widowed patients (for all $\mathrm{p}>0.05$ ). There were significant differences between educational levels of the patients in terms of the mean WHOQOL-BREF scores $(\mathrm{p}<0.05)$. The mean scores increased as educational levels increased. Conclusion: Quality of life increases with the levels of education and does not differ according to gender and marital status in patients with muscular dystrophy. Patients with muscular dystrophy should be encouraged for education from the pediatric period.
\end{abstract}

\section{Hosted file}

WHOQoL_Manuscript.pdf available at https://authorea.com/users/403632/articles/515040evaluation-of-the-quality-of-life-and-sociodemographic-features-of-patients-withmuscular-dystrophies 

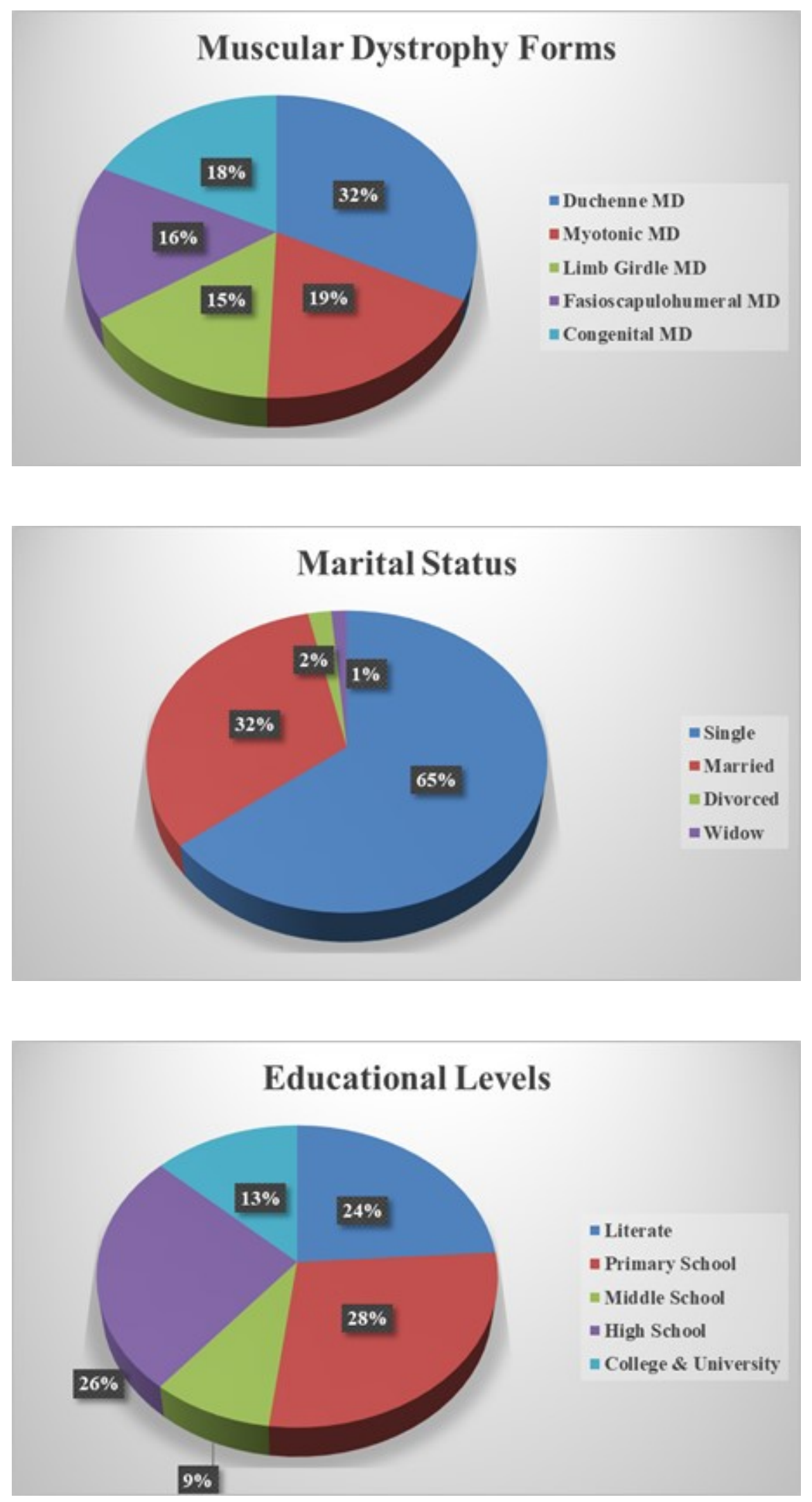